Revista Destaques Acadêmicos, Lajeado, v. 11, n. 3, 2019. ISSN 2176-3070

DOI: http://dx.doi.org/10.22410/issn.2176-3070.v11i3a2019.2260

http://www.univates.br/revistas

\title{
OS CAMINHOS DAS PRÁTICAS INTEGRATIVAS E COMPLEMENTARES NA ATENÇÃO BÁSICA: UMA REVISÃO INTEGRATIVA
}

\author{
Andresa Coloia dos Santos ${ }^{1}$, Eunice de Fatima Soares da Cunha ${ }^{2}$
}

\begin{abstract}
Resumo: O estudo teve o objetivo de discutir acerca dos processos de implementação das Práticas Integrativas e Complementares no SUS, fomentando subsídios teóricos sobre a temática, por meio de uma revisão integrativa, na qual realizou-se levantamento de artigos científicos, durante o mês de Março, do ano de 2019, nas bases de dados: Medline via Biblioteca Virtual de Saúde (Bireme), Literatura Latino-Americana e do Caribe em Ciências da Saúde (Lilacs). Os descritores utilizados foram "Terapias complementares" AND "Saúde pública" AND "Brasil", todos presentes no Descritores da Ciência da Saúde (DESC). Foram encontrados 501 artigos, 334 na Lilacs e 166 na Medline. Após a leitura dos títulos foram excluídos 436 artigos, restando 65 artigos. No decorrer do processo de seleção, 35 artigos, após leitura do resumo, também foram excluídos. Dos 35 artigos selecionados, 02 foram excluídos por repetição e 23 por não atenderem a temática proposta pelo presente estudo após a leitura na íntegra. Compuseram a amostra final, 05 artigos. Os estudos comprovam a eficácia das práticas integrativas e complementares na atenção básica e na melhora da qualidade de vida da população. Observa-se pelo descrito nos trabalhos selecionados que, mesmo sendo uma política eficaz, ainda há falta de conhecimento sobre as práticas integrativas e complementares na saúde, bem como, pouca adesão dessa política no município pelo gestor.
\end{abstract}

Palavras-chave: terapias complementares, saúde pública, Brasil.

\section{INTRODUÇÃO}

Desde os primórdios da humanidade, a saúde é tida como um bem valioso, ao qual os seres sempre se empenharam em manter, porém não muito diferente do que ocorre nos dias atuais o conceito de saúde reflete a conjuntura social, econômica, política e cultural. Sendo assim não representa a mesma coisa

1 Bacharel em Enfermagem. Centro Universitário dos Guararapes (UNIG),Campus/Piedade, Jaboatão dos Guararapes - PE. coloiasantos@gmail.com

2 Bacharel em Enfermagem. Centro Universitário dos Guararapes (UNIG),Campus/Piedade, Jaboatão dos Guararapes - PE. nice.006@hotmail.com 
para todas as pessoas dependerá da época, do lugar, da classe social, dependerá de valores individuais, de concepções científicas, religiosas, filosóficas. Pode ser dito assim que, aquilo que é considerado doença varia muito conforme a ciência avança (SCLIAR, 2007).

A Biologia e a Medicina são ciências independentes, que sempre caminharam juntas, em seu desenvolvimento no decorrer da história, da ciência ocidental moderna. $\mathrm{Na}$ base do pensamento biológico, por influência de Descartes, está a concepção cartesiana, na qual se reduz os organismos vivos a seus menores constituintes, essa influência do modelo cartesiano sobre o pensamento médico deu origem ao chamado modelo biomédico (CAPRA, 1982).

Durante a década de 40, a Organização Mundial de Saúde (OMS) propôs um novo conceito de saúde que possui críticas sustentada até os dias atuais, por ser considerado um conceito utópico. Foi o início de um grande passo, para o reconhecimento do direito à saúde e da obrigação do Estado na promoção e proteção da saúde,"Saúde é o estado do mais completo bem-estar físico, mental e social e não apenas a ausência de enfermidade" (BRASIL, 1979).

As novas descobertas e a valorização do que antes chamava-se "medicina complementar" possibilitou no campo da saúde novas abordagens ao lidar com o adoecimento. Criou-se novas formas de nele intervir, o termo holístico passa a permear as ciências, surgem discussões sobre a integralidade em saúde e a produção do cuidado com vistas à transformação do modelo técnico-assistencial (LO et al. 2013).

A Reforma Sanitária no Brasil foi um marco histórico em âmbito político, ético econômico e social, no que tange a saúde. Impulsionada durante a década de oitenta pela Oitava Conferência Nacional de Saúde, objetivava uma discussão mais abrangente do conceito em saúde e alternativas, que pudessem garantir sua justa implementação, percebendo o doente em sua totalidade, descaracterizando uma saúde baseada em métodos hospitalocêntricos para analisar os determinantes e condicionantes em saúde que poderiam ser responsáveis pelas mazelas sociais da época apoiada na Medicina Social. A Oitava Conferência Nacional de Saúde teve como diferencial a livre participação da sociedade e de movimentos sociais e partidários (PAIVA; TEXEIRA, 2014).

Os registros da história da medicina mostram que o cuidado em saúde teve diferentes modelos, desenvolvidos de acordo com o contexto e as bases culturais e materiais de cada época. $\mathrm{O}$ modelo ocidental atual mais utilizado em saúde é o biomédico, o qual apresenta fantásticas soluções para problemas de detecção e diagnósticos de doenças. No entanto, há algumas décadas tem sido fonte crescente de insatisfação da população, devido a sua dicotomia do cuidado e à superespecialização nas diversas áreas da medicina (OTANI; BARROS, 2019). 
A origem das práticas integrativas nos sistemas públicos de saúde, datam do final dos anos 70, com a Primeira Conferência Internacional de Assistência Primária em Saúde. A partir de Alma Ata a Organização Mundial de Saúde criou o Programa de Medicina Tradicional, objetivando a formulação de políticas em defesa dos conhecimentos tradicionais em saúde (TELESI JUNIOR, 2016).

Para Luz (1996), formas simplificadas e não invasivas, consumo de medicamentos oriundos de produtos naturais e uma proposta ativa de promoção da saúde, fazem parte de sistemas terapêuticos e práticas de medicação e cuidado, desde a segunda metade da década de 70 .

No campo da saúde há hoje, uma procura por novas abordagens no que tange à questão do adoecimento e às formas de nele intervir, valorizando o indivíduo. Juntamente a tais abordagens, observa-se nos últimos anos uma crescente aceitação das Terapias Complementares em nossa sociedade (MELO et al., 2013).

Em 2006, o Ministério da Saúde implantou a Política Nacional de Práticas Integrativas e Complementares (PNPIC), que rege a inserção destas práticas no Sistema Único de Saúde, dispondo sobre sua implantação no contexto nacional. O campo das PICS contempla sistemas médicos complexos e recursos terapêuticos conhecidos sob várias denominações, como tradicionais, complementares, integrativas, alternativas ou não convencionais (MS, 2006).

Esta política veio atender, sobretudo, a necessidade de se conhecer, apoiar, incorporar e implementar experiências que já vinham sendo desenvolvidas na rede pública de muitos municípios e estados respondendo ao mesmo tempo ao desejo de parte da população, manifestada nas recomendações de Conferências Nacionais de Saúde, desde 1988 (ISCHKANIAN, 2011).

A PNPIC contribui com o fortalecimento dos princípios fundamentais do SUS, podendo assim, ser entendida como mais um passo no processo de sua implantação. Tais práticas atuam nos campos da; prevenção de agravos e da promoção, manutenção e recuperação da saúde baseada em modelo de atenção humanizada, observando o indivíduo em sua dimensão global, mas centrada em sua integralidade. Além disso, o uso da Medicina Alternativa e Complementar (MAC) no SUS permite uma abertura de possibilidades preventivas e terapêuticas antes restritas à prática privada (BRASIL, 2006).

Segundo o Centro Nacional de Medicina Complementar e Alternativa dos Estados Unidos (NCCAM), MAC é o conjunto de diversos sistemas, práticas e produtos médicos e de atenção à saúde que não se consideram, atualmente, parte da medicina convencional (NETO et al., 2010).

Mesmo estando em crescimento, as dificuldades relativas à adoção das práticas integrativas e complementares com bases essencialmente nas medicinas tradicionais são visíveis. Para Tesser e Barros (2008), a hegemonia 
político epistemológica da Biociência e a disputa mercadológica atual no campo da saúde, devem ser observadas como fatores importantes.

Segundo o Ministério da Saúde, em seu portal de notícias oficial, o uso das práticas integrativas no Sistema Único de Saúde (SUS) vem crescendo a cada ano, Por isso, o Ministério da Saúde, a partir da Política Nacional de Práticas Integrativas e Complementares, passou a ofertar um rol de 29 práticas integrativas, entre o ano de 2017 a 2018, houve um aumento de $48 \%$ do número de adeptos, principalmente em atividades, como a yoga e o tai chi chuan, já a auriculoterapia mais que dobrou (PORTAL DA SAÚDE, 2019).

Diante do exposto, faz-se necessário compreender o conceito, aplicação e eficácia das Terapias Complementares na saúde pública, brasileira, representada pelo SUS (Sistema Único de Saúde), tornando esse conhecimento acessível a estudantes e profissionais da área da saúde fomentando conteúdo teórico e crítico sobre a temática.

\subsection{Terapias complementares: Aporte Histórico}

Durante a Idade Média passa a ser necessário separar o binômio saúde/ doença para que se pudesse evoluir no tratamento, diagnóstico e entender os sinais e sintomas de algumas patologias. Assim tem-se um conceito fechado, do que é saúde e do que é doença. O ser humano se questiona sobre a origem da vida, as razões da existência e o que é ter saúde. Do mesmo modo, parece-nos que todo profissional de saúde deveria colocar-se diante de um questionamento essencial e existencial semelhante: O que é a saúde? e Como meu trabalho pode efetivamente se tornar um meio de promovê-la? (GUTIERREZ; OBERDIEK, 2001).

Os egípcios consideravam a saúde como o estado natural do ser humano e mantinham relação com as alterações ocorridas com o Rio Nilo, razão de sua subsistência. Praticavam hábitos de higiene, fazendo uso de banhos e acreditavam que alimentos bem ou mal combinados podiam manter a saúde ou causar doenças, observando a esse processo de permanência ou não por uma ótica ritualística com crenças místicas (LINDEMBERG, 2006).

O conceito de saúde encontra sua gênese na íntima relação entre filosofia e medicina, na influência mútua entre ambos desde suas origens. $\mathrm{O}$ pai da medicina ocidental Hipócrates, identificou a saúde como fruto do equilíbrio dos humores sendo a doença, por oposição, resultante do desequilíbrio dos mesmos. Entendia o homem como uma unidade organizada e a doença como uma desorganização desse estado, seu equilíbrio total resultaria na saúde. A saúde, segundo Platão, consistia na descoberta da estrutura do corpo (pelo médico) e da estrutura da alma pelo filósofo (AIUB; NEVES, 2005).

Durante a Idade Média e o Período Medieval, a saúde encontravase presa a dogmas da Igreja, que também era responsável pelos primeiros hospitais, apesar de considerar que as doenças demonstravam uma alteração 
dos humores. A causa da alteração era o pecado as quais eram vistas como possessão demoníaca, feitiçaria ou mesmo uma forma de purificação destes pecados assim, o único meio de alcançar a cura era a súplica por perdão (ARAUJO; PAZ; MOREIRA, 2012).

A Idade Moderna foi marcada sobretudo pela época do Renascimento, que caracterizou-se pela eclosão de manifestações artísticas, filosóficas e científicas do novo mundo urbano e burguês, os estudos empíricos originariam a formação das ciências básicas e com isto surge a necessidade de se descobrir a origem das matérias que causavam os contágios. Surge, neste período, a teoria miasmática (GUTIERREZ; OBERDIEK, 2001).

Na concepção proposta por Foucault em 1982, com a evolução do Estado, a saúde passa a ter "valor" dentro da sociedade, vista também como forma comercial e como fonte de poder e riqueza para o fortalecimento dos países, desta forma, a patologia passa a ser objeto das intervenções médicas, surgindo o modelo biomédico. Com isso, cuida-se da doença e não mais do ser humano (LOURENÇO et al., 2014).

Com o avançar do tempo e influenciada pelas consequências do pós-guerra surge a Organização Mundial da Saúde (OMS), uma agência especializada das Nações Unidas. Fundada em 7 de abril de 1948, que tem como foco lidar com questões relativas à saúde global, possuindo o entendimento de saúde como um estado de completo bem-estar físico, mental e social, e não consiste apenas na ausência de doença ou de enfermidade (OMS, 1946).

Um marco importante para a saúde foi à inserção do pensamento do que é promoção da saúde, denominada assim, no início do século $X X$, por Henry Sigerist, que resulta em quatro funções da medicina: Promoção da Saúde, Prevenção das Doenças, Tratamento dos Doentes e Reabilitação bem como os estudos dos sanitaristas, Leavell Clark, sanitaristas que através do modelo explicativo da "história natural do processo saúde-doença", diferenciaram a promoção da saúde da prevenção de doença (WESTPHAL, 2007).

A produção científica e política européia, sobre a determinação social do processo saúde/doença no século XIX, gerou a Medicina Social e foi sem dúvida, uma das precursoras modernas da promoção da saúde. Em setembro de 1978 foi realizada a primeira Conferência Internacional sobre Cuidados Primários de Saúde, organizada pela OMS e UNICEF em Alma-Ata. O tema dessa primeira conferência era Saúde Para Todos no Ano 2000, resultando na adoção de uma Declaração que reafirmou o significado da saúde, como um direito humano fundamental (MENDES, 2004).

A partir deste movimento surgido na década de 70 , se configura na década de 80, um processo denominado por Buss (1998), de estratégia da "Nova Promoção da Saúde", que tem seu desenvolvimento, como movimento ideológico e social, de forma mais intensa, no Canadá, Estados Unidos e países 
da Europa Ocidental. Nos anos 70, com avanços mais lentos na América Latina e Caribe.

\subsection{Terapias Complementares e Integrativas e sua implantação no Brasil}

As Conferências Internacionais, desde a Primeira Conferência Internacional de Promoção da Saúde, realizada em Ottawa em 1986, têm difundido conceitos básicos, que exigem o fortalecimento da saúde pública, em torno do compromisso de saúde para todos. As discussões de Ottawa tiveram como parâmetro a Declaração de Alma-Ata para os Cuidados Primários em Saúde (1978) e debates posteriores realizados ao redor do mundo (ANDRADE; BARRETO, 2002).

Com a Primeira Conferência Internacional de Assistência Primária em Saúde (Alma Ata, Rússia, 1978), as primeiras recomendações para a implantação das medicinas tradicionais e práticas complementares difundiram-se em todo o mundo. A OMS desenvolve o Programa de Medicina Tradicional, objetivando a formulação de políticas em defesa dos conhecimentos tradicionais em saúde, firmando o compromisso de incentivar os Estados-membro a formularem políticas públicas para uso racional e integrado das Medicinas Tradicionais e das Medicinas Complementares e Alternativas nos sistemas nacionais de atenção à saúde, bem como para o desenvolvimento de estudos científicos para melhor conhecimento de sua segurança, eficácia e qualidade (TELESI JUNIOR, 2016).

No Brasil, surge na década de 70, um movimento postulando a democratização da saúde, justamente num período no qual novos sujeitos sociais emergiram nas lutas contra a ditadura. $\mathrm{O}$ Movimento da Reforma Sanitária Brasileira (MRSB), constituiu-se no processo de amplas mobilizações da sociedade brasileira. Configurou-se como ação política centrada em torno de um projeto civilizatório de sociedade inclusiva, solidária, tendo a saúde como direito universal de cidadania (AROUCA, 2003).

A Reforma Sanitária Brasileira foi proposta num momento de intensas mudanças e sempre pretendeu ser mais do que apenas uma reforma setorial. Almejava-se, desde seus primórdios, que pudesse servir à democracia e à consolidação da cidadania no País. A realidade social, na década de oitenta, era de exclusão da maior parte dos cidadãos do direito à saúde, que se constituía na assistência prestada pelo Instituto Nacional de Previdência Social (PAIVA; TEXEIRA, 2014).

Impulsionados por essa reforma, a saúde pública se consolida amplamente através da $8^{\mathrm{a}}$ Conferência Nacional de Saúde, realizada em 1986, com uma proposta de saúde que observa-se o sujeito de forma integral e universal, sendo esta a primeira com participação social livre, precedida de pré-conferências municipais, estaduais e de profissionais do ramo, foram 
estabelecidas as condições para assegurar com mais eficácia o direito à saúde. (AROUCA, 2003).

A $8^{a}$ Conferência Nacional de Saúde (CNS) deliberou em seu relatório final a introdução de práticas alternativas de assistência à saúde no âmbito dos serviços de saúde, possibilitando ao usuário o acesso democrático de escolher a terapêutica preferida. Outras recomendações de implantação (BRASIL, 2006).

Porém conforme os anos passavam, o Brasil continuava enfrentando graves problemas socioeconômicos e um descontentamento da sociedade em relação ao modelo assistencial oferecido pelo SUS. Em 2003 foi realizada a $12^{a}$ Conferência Nacional de Saúde, com o propósito de reafirmar o direito à saúde pública e de qualidade para toda a população, pretendeu-se adotar um modelo centrado na saúde, nas capacidades da natureza e da ciência, e não na doença e nas conveniências do mercado farmacológico e tecnológico (BRASIL, 2003).

Em 2003 constitui-se um Grupo de Trabalho responsável pela elaboração de uma proposta de Política Nacional, com o intuito de oferecer outras opções terapêuticas, para melhor atender à população, que incorporassem os princípios da cultura e saberes locais. Em 2006 o Ministério da Saúde publicou, a Política Nacional de Práticas Integrativas e Complementares no SUS (PNPIC) (BRASIL, 2006).

Esta política atende sobretudo, à necessidade de se conhecer, apoiar, incorporar e implementar experiências que já vinham sendo desenvolvidas na rede pública de muitos municípios e estados, entre as quais se destacam aquelas no âmbito da medicina tradicional chinesa/acupuntura, da homeopatia, da fitoterapia, da medicina antroposófica e do termalismo/crenoterapia. A partir das experiências existentes, define-se as abordagens da PNPIC no SUS, levando em conta também a crescente legitimação destas por parte da sociedade a PNPIC contribui assim para o fortalecimento dos princípios fundamentais do SUS (BRASIL, 2015).

Em 2011 as PICS foram inseridas no Programa Nacional de Melhoria do Acesso e da Qualidade na Atenção Básica (PMAQ-AB). Em 2012 diversos padrões de PICS foram inseridos no e-SUS e no Sisab, que posteriormente permitiram o monitoramento de ações de PICS na AB. Em 2013, o Ministério da Saúde, através de parceria com o Conselho Nacional de Desenvolvimento Científico e Tecnológico (CNPq), publicou um edital de fomento à pesquisa e contemplou 28 projetos de pesquisa de interesse do SUS (AMADO et al., 2017).

Em 2014 foram lançados na Comunidade de Práticas, plataforma virtual interativa, dois cursos, um de Gestão em PICS e outro de Plantas Medicinais voltados para os Agentes Comunitários de Saúde (ACS). Em 2015, criou-se a Rede Nacional de Atores Sociais em PICS (RedePICS) com o objetivo de instituir canais de comunicação entre as PICS e as diversas instituições públicas, além de promover fóruns de debate para temas prioritário promover a articulação e interação entre os diversos atores a fim de gerar informações, produzir notícias, 
monitorar e assessorar o processo de implementação da PNPIC (AMADO, 2017).

Em 2016 foram inseridos os procedimentos na tabela do Sistema de Gerenciamento da Tabela de Procedimentos e Medicamentos (SIGTAP) e Órteses, Próteses e Materiais Especiais (OPM) do SUS, terapia comunitária, dança circular/ biodança, yoga, oficina de massagem/ automassagem, sessão de auriculoterapia, sessão de massoterapia, orientação de tratamento termal/ crenoterápico, o que significou a primeira ampliação de procedimentos das PICS em oito anos (MS, 2017).

Em 2017 houve a alteração do código de alguns procedimentos e inclusão na tabela os procedimentos de arteterapia, meditação, musicoterapia, tratamento naturopático, tratamento osteopático, tratamento quiroprático e reiki. Em março do mesmo ano, houve a ampliação da PNPIC em 14 novas práticas: Arteterapia, Ayurveda, Biodança, Dança Circular, Meditação, Musicoterapia, Naturopatia, Osteopatia, Quiropraxia, Reflexoterapia, Reiki, Shantala, Terapia Comunitária Integrativa e Yoga (BRASIL, 2018).

Em março de 2018 pacientes do Sistema Único de Saúde (SUS) foram beneficiados com 10 novas (PICS),voltadas para prevenir diversas doenças, como depressão e hipertensão. São elas: apiterapia, aromaterapia, bioenergética, constelação familiar, cromoterapia, geoterapia, hipnoterapia, imposição de mãos, ozonioterapia e terapia de florais. O Brasil passa a contar com 29 práticas integrativas pelo SUS. Com isso, somos o país líder na oferta dessa modalidade na atenção básica. As Práticas Integrativas e Complementares não substituem o tratamento tradicional. Elas são um adicional, um complemento no tratamento e indicadas por profissionais específicos conforme as necessidades de cada caso (MS, 2018).

\section{MÉTODO}

A presente pesquisa trata-se de um estudo bibliográfico, descritivo do tipo revisão integrativa da literatura, definida como aquela em que resultados de pesquisas sobre um determinado assunto ou questionamento são analisados e sintetizados, com o propósito de aprofundar o conhecimento sobre um tema em particular.

Realizou-se levantamento de artigos científicos, que ocorreram durante o mês de Março, do ano de 2019, nas seguintes bases de dados: Medline via Biblioteca Virtual de Saúde (Bireme), Literatura Latino-Americana e do Caribe em Ciências da Saúde (Lilacs). Os descritores utilizados foram: " Terapias complementares " AND "Saúde pública" AND "Brasil", todos presentes no Descritores da Ciência da Saúde (DESC), utilizando o cruzamento de palavras como disposto no Quadro 1. 
Quadro 1 - Estratégias de busca para consulta nas bases de dados

\begin{tabular}{|c|c|c|}
\hline $\begin{array}{c}\text { Cruzamentos em } \\
\text { português }\end{array}$ & Cruzamentos em Inglês & Cruzamentos em Espanhol \\
\hline TERAPIAS & COMPLEMENTARY & TERAPIAS \\
COMPLEMENTARES & THERAPIES AND & COMPLEMENTARIAS \\
AND BRASIL & BRAZIL & AND BRASIL \\
\hline TERAPIAS & COMPLEMENTARY & TERAPIAS \\
COMPLEMENTARES & THERAPIES AND & COMPLEMENTARIAS \\
AND SAÚDE PÚBLICA & PUBLIC HEALTH & AND SALUD PUBLICA \\
\hline BRASIL AND SAÚDE & BRAZIL AND PUBLIC & BRASIL AND SALUD \\
PÚBLICA & HEALTH & PUBLICA \\
\hline
\end{tabular}

Foram estabelecidos os seguintes critérios de inclusão: artigos que abordavam temática sobre a eficácia e a utilização das terapias complementares na saúde pública brasileira, nos idiomas português, inglês e espanhol, sem delimitação de país de publicação e com delimitação atemporal. Como critérios de exclusão optou-se por excluir artigos que fugiram da temática proposta pela pesquisa, manuais técnicos, revisões de literatura, monografias, teses, dissertações e artigos que não se encontravam disponíveis para acesso.

Em relação a pesquisa nas bases de dados, foram encontrados um total de 501 artigos, 334 na Lilacs e 166 na Medline. Após a leitura dos títulos foram excluídos 436 artigos, restando um total de 65 artigos. No decorrer do processo de seleção excluiu-se 35 artigos após a leitura do resumo do artigo, restantando um total de 35 artigos, sendo 02 excluídos por repetição, e 23 por não atenderem a temática proposta pelo presente estudo após a leitura na íntegra. Esta etapa foi realizada por três revisores independentes, que utilizaram, o consenso para a seleção dos artigos a serem utilizados pela a pesquisa, totalizando uma amostra de 05 artigos. Conforme fluxograma disposto na Figura 1. 
Figura 1 - Fluxograma

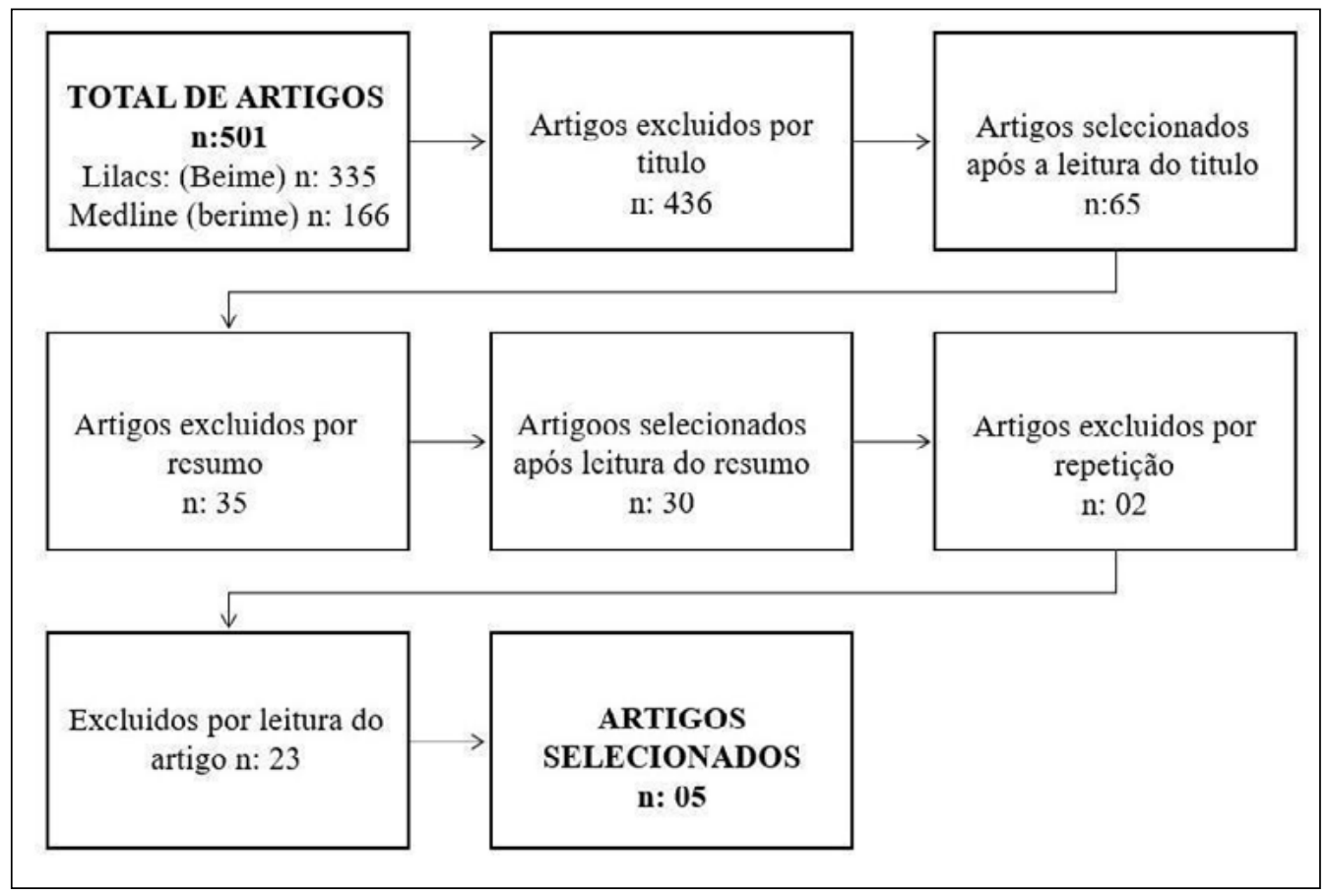

Nos artigos encontrados classificamos segundo a qualidade em níveis de evidências, são sete níveis: Nível 1, as evidências provenientes de revisão sistemática ou metanálise de relevantes ensaios clínicos randomizados controlados ou oriundas de diretrizes clínicas baseadas em revisões sistemáticas de ensaios clínicos randomizados controlados; Nível 2, evidências derivadas de pelo menos um ensaio clínico randomizado controlado bem delineado; Nível 3, evidências obtidas de ensaios clínicos bem delineados sem randomização; Nível 4, evidências provenientes de estudos de coorte e de caso controle bem delineados; Nível 5, evidências originárias de revisão sistemática de estudos descritivos e qualitativos; nível 6, evidências derivadas de um único estudo descritivo ou qualitativo; Nível 7, evidências oriundas de opinião de autoridades e/ou relatório de comitês de especialistas)

\section{RESULTADOS}

\subsection{Descrição dos artigos}

A amostra final resultou em um quantitativo de 05 artigos, a partir disso constatou-se uma variação de tempo dos artigos incluídos na pesquisa entre 2009 a 2017. Sobre o local de publicação, predominou-se o estado do Rio de Janeiro o total de 03 artigos, 01 no estado de São Paulo e 01 no estado da Paraíba. Os idiomas das publicações apenas um estudo foi escrito na língua 
inglesa. Identificou-se que todas as publicações classificaram-se no nível VI de evidência científica. O Quadro 1, apresenta a seleção dos artigos ao final das buscas nas bases de dados.

Quadro 1- Seleção dos artigos da amostra final. Jaboatão - PE, 2019

\begin{tabular}{|c|c|c|c|c|c|}
\hline Título do artigo/ autor & Periódico & $\begin{array}{c}\text { Local de } \\
\text { publicação }\end{array}$ & Idioma & Ano & $\begin{array}{l}\text { Nível de } \\
\text { evidência }\end{array}$ \\
\hline $\begin{array}{l}\text { 1. As práticas integrativas } \\
\text { na estratégia saúde da } \\
\text { família: Visão dos agentes } \\
\text { comunitários de saúde } \\
\text { Paranaguá et al }\end{array}$ & $\begin{array}{l}\text { Rev. Enferm } \\
\text { UERJ; } \\
\text { 17(1):75-0 }\end{array}$ & $\begin{array}{c}\text { Rio de } \\
\text { Janeiro } \\
\text { (RJ) }\end{array}$ & Português & 2009 & VI \\
\hline $\begin{array}{l}\text { 2. Percepção de médicos } \\
\text { e enfermeiros da } \\
\text { Estratégia de Saúde da } \\
\text { Família sobre terapias } \\
\text { complementares } \\
\text { Thiago, S.C.S Tesser, D.C }\end{array}$ & $\begin{array}{l}\text { Rev. Saúde } \\
\text { Pública; } \\
\text { 45(2):249-57 }\end{array}$ & $\begin{array}{l}\text { São Paulo } \\
\text { (SP) }\end{array}$ & Português & 2010 & VI \\
\hline $\begin{array}{l}\text { 3. Práticas integrativas } \\
\text { e complementares: } \\
\text { oferta e produção } \\
\text { de atendimentos no } \\
\text { SUS e em municípios } \\
\text { selecionados } \\
\text { Sousa et al. }\end{array}$ & $\begin{array}{c}\text { Cad. Saúde } \\
\text { Pública, Rio } \\
\text { de Janeiro, } \\
\text { 28(11):2143-2154, } \\
\text { nov, }\end{array}$ & $\begin{array}{l}\text { Rio de } \\
\text { Janeiro } \\
\text { (RJ) }\end{array}$ & Português & 2012 & VI \\
\hline $\begin{array}{c}\text { 4. Experiência de } \\
\text { pacientes com } \\
\text { acupuntura no Sistema } \\
\text { Único de Saúde em } \\
\text { diferentes ambientes } \\
\text { de cuidado e (des) } \\
\text { medicalização social } \\
\text { Silva, C.D.E Tesser, D.C }\end{array}$ & $\begin{array}{c}\text { Cad. Saúde } \\
\text { Pública, Rio } \\
\text { de Janeiro, } \\
\text { 29(11):2186-2196, } \\
\text { nov, }\end{array}$ & $\begin{array}{l}\text { Rio de } \\
\text { Janeiro } \\
\text { (RJ) }\end{array}$ & Português & 2013 & VI \\
\hline $\begin{array}{l}\text { 5. Fitoterapia na atenção } \\
\text { básica: estudo com } \\
\text { profissionais enfermeiros } \\
\text { Oliveira et al. }\end{array}$ & $\begin{array}{l}\text { J. res.: fundam. } \\
\text { care. online abr./ } \\
\text { jun. } \\
\text { 9(2): } 480-487\end{array}$ & $\begin{array}{c}\text { Cabedelo } \\
\text { (PB) }\end{array}$ & Inglês & 2017 & VI \\
\hline
\end{tabular}

O Quadro 2 mostra a caracterização da análise dos artigos referente ao objetivo, desenho metodológico das pesquisas, amostra e considerações finais dos estudos selecionados. 
Quadro 2 - Síntese dos artigos incluídos nesta revisão integrativa. Jaboatão PE, 2019

\begin{tabular}{|c|c|c|c|c|}
\hline & Objetivo(s) & $\begin{array}{l}\text { Desenho do } \\
\text { Estudo }\end{array}$ & Amostra & Considerações \\
\hline 1 & $\begin{array}{c}\text { Investigar o uso de } \\
\text { práticas integrativas pela } \\
\text { população atendida nas } \\
\text { ESF e a interseção destes } \\
\text { agentes junto à clientela. }\end{array}$ & $\begin{array}{c}\text { Descritivo, } \\
\text { Exploratório, } \\
\text { Abordagem } \\
\text { quanti- } \\
\text { qualitativa, }\end{array}$ & $\begin{array}{c}\text { Participaram } \\
35 \text { (ACS),que } \\
\text { dispuseram a } \\
\text { participar }\end{array}$ & $\begin{array}{l}\text { A pesquisa revelou que o uso } \\
\text { das práticas integrativas foi } \\
\text { ressaltado pelos ACS e destacadas } \\
\text { a homeopatia, a fitoterapia, a } \\
\text { acupuntura, os chás medicinais, a } \\
\text { massoterapia, o yoga é a shantala, } \\
\text { sendo o uso relacionado tanto à } \\
\text { promoção quanto à recuperação da } \\
\text { saúde. Os resultados satisfatórios e } \\
\text { as crenças nessas práticas são fatores } \\
\text { que levam o ACS a indicá-las às } \\
\text { famílias assistidas. }\end{array}$ \\
\hline 2 & $\begin{array}{l}\text { Analisar a percepção } \\
\text { de profissionais da ESF } \\
\text { sobre as PIC. }\end{array}$ & $\begin{array}{c}\text { Descritiva, } \\
\text { Exploratória }\end{array}$ & $\begin{array}{c}82 \text { médicos } \\
95 \text { enfermeiros. }\end{array}$ & $\begin{array}{l}\text { A pesquisa evidenciou a oferta de } \\
\text { múltiplas opções terapêuticas e } \\
\text { de cuidado por meio das práticas } \\
\text { integrativas e complementares é } \\
\text { uma possibilidade nos municípios } \\
\text { brasileiros e uma realidade em vários } \\
\text { deles, incentivada pela PNPIC. Os } \\
\text { resultados da pesquisa sugerem que } \\
\text { há apoio dos médicos e enfermeiros } \\
\text { da ESF da rede municipal de } \\
\text { saúde de Florianópolis para a } \\
\text { implantação das PIC. Esse apoio } \\
\text { pode existir em grau significativo } \\
\text { em outros municípios do País e seu } \\
\text { levantamento pelos gestores pode } \\
\text { ser um importante primeiro passo } \\
\text { para a construção sustentável de } \\
\text { políticas locais de oferta das terapias } \\
\text { complementares no SUS. }\end{array}$ \\
\hline 3 & $\begin{array}{c}\text { Analisar as } \\
\text { características da } \\
\text { oferta e produção de } \\
\text { práticas integrativas } \\
\text { e complementares no } \\
\text { SUS entre os anos } 2000 \\
\text { e } 2011 .\end{array}$ & $\begin{array}{c}\text { Descritiva, } \\
\text { Exploratória }\end{array}$ & $\begin{array}{l}\text { base em bancos } \\
\text { de dados } \\
\text { nacionais } \\
\text { sobre oferta, } \\
\text { profissionais } \\
\text { e produção, } \\
\text { vis-à-vis dados } \\
\text { primários da } \\
\text { atenção primária } \\
\text { em saúde, } \\
\text { coletados nos } \\
\text { municípios } \\
\text { de Campinas, } \\
\text { Florianópolis e } \\
\text { Recife. }\end{array}$ & $\begin{array}{l}\text { A pesquisa mostrou que o incentivo } \\
\text { da Política Nacional de Práticas } \\
\text { Integrativas e Complementares } \\
\text { para inserção e fortalecimento } \\
\text { dessas práticas nos níveis primários } \\
\text { de atenção esbarra em alguns } \\
\text { obstáculos. O que pode parecer } \\
\text { flexibilidade, ou seja, a não definição } \\
\text { clara do escopo do termo práticas } \\
\text { complementares e integrativas, } \\
\text { significa uma grande limitação para a } \\
\text { avaliação e o monitoramento de sua } \\
\text { oferta e resultados }\end{array}$ \\
\hline
\end{tabular}




\begin{tabular}{|c|c|c|c|c|}
\hline & Objetivo(s) & $\begin{array}{c}\text { Desenho do } \\
\text { Estudo }\end{array}$ & Amostra & Considerações \\
\hline 4 & $\begin{array}{l}\text { Investigar a experiência } \\
\text { de usuários de } \\
\text { acupuntura do SUS } \\
\text { de Florianópolis, } \\
\text { Santa Catarina, } \\
\text { Brasil, sobre seu } \\
\text { tratamento, incluindo } \\
\text { sua percepção sobre } \\
\text { eficácia, redução do } \\
\text { uso de medicamentos, } \\
\text { orientações recebidas, } \\
\text { mudanças no } \\
\text { autocuidado e nos } \\
\text { modelos explicativos } \\
\text { dos usuários, do } \\
\text { ponto de vista da } \\
\text { medicalização no foco } \\
\text { supramencionado. }\end{array}$ & $\begin{array}{l}\text { Descritiva, } \\
\text { Qualitativa }\end{array}$ & $\begin{array}{l}30 \text { usuários } \\
\text { entrevistados }\end{array}$ & $\begin{array}{l}\text { Verificou-se que à acupuntura na } \\
\text { atenção secundária quando outros } \\
\text { tratamentos falharam e em estágios } \\
\text { avançados de adoecimento. Mesmo } \\
\text { nesses casos, ela foi percebida pela } \\
\text { maioria dos usuários com relativa } \\
\text { eficácia sob vários aspectos, com } \\
\text { melhoria de seus sofrimentos e } \\
\text { quadros álgicos e redução do uso } \\
\text { de medicamentos. Esse é um ponto } \\
\text { importante, devendo ser mais bem } \\
\text { estudada a hipótese da utilização da } \\
\text { acupuntura significar efetivamente } \\
\text { redução de uso, danos e custos com } \\
\text { medicamentos. }\end{array}$ \\
\hline 5 & $\begin{array}{c}\text { Investigar a } \\
\text { compreensão de } \\
\text { enfermeiros sobre } \\
\text { fitoterapia e determinar } \\
\text { as estratégias necessárias } \\
\text { para consolidar essa } \\
\text { prática na atenção } \\
\text { básica. }\end{array}$ & $\begin{array}{c}\text { Descritiva, } \\
\text { Exploratória, } \\
\text { Qualitativa }\end{array}$ & $\begin{array}{l}10 \text { Enfermeiros } \\
\text { de USF }\end{array}$ & $\begin{array}{l}\text { A pesquisa mostrou que as evidências } \\
\text { científicas e a implementação de } \\
\text { políticas públicas no SUS, atreladas } \\
\text { a práticas antigas que persistem até } \\
\text { os dias atuais, revelam e confirmam } \\
\text { a magnitude da Fitoterapia, cujo } \\
\text { objetivo primordial é promover e } \\
\text { restabelecer a saúde da população } \\
\text { em geral, mais especificamente, no } \\
\text { contexto da atenção primária. Em } \\
\text { relação à compressão do profissional } \\
\text { de enfermagem sobre fitoterapia } \\
\text { na atenção primária, observou- } \\
\text { se no presente estudo a falta de } \\
\text { compreensão, revelando uma } \\
\text { deficiência na formação que visa } \\
\text { proporcionar uma assistência integral } \\
\text { à população, baseada na promoção } \\
\text { da qualidade de vida. }\end{array}$ \\
\hline
\end{tabular}

\section{DISCUSSÃO}

As publicações encontradas, apresentam posicionamentos acordantes em relação ao futuro da PNPIC, fomentando subsídios teóricos que comprovam a eficácia das práticas na atenção básica e no melhoramento da qualidade de vida da população, fazendo menção a obstáculos importantes, a serem discutidos, sobre implementação e desenvolvimento científico na atenção básica, que permeiam tanto sobre a validação das terapêuticas, bem como o financiamento para estímulo das mesmas. O que demonstra uma resistência, que impossibilita de forma mesmo que indireta, o conhecimento das práticas pela população contemplada no território das unidades de saúde, bem como a inclusão dessa política no município pelo gestor. 
As práticas integrativas e complementares, não possuem um caráter substitutivo a medicina tradicional/alopática, e sim um caráter complementar ao cuidado em saúde, respeitando a particularidade de cada indivíduo, e seus desejos enquanto sujeito social envolvido nesse processo de cuidar, de estimular o autocuidado e a responsabilidade.

A introdução no SUS das práticas integrativas e complementares, através da Portaria ${ }^{\circ} 971$ de 03 de maio de 2006, reafirma o conceito ampliado de saúde descrita na Constituição em seu artigo $3^{\circ}$, que garante a integralidade, na medida em que direciona o olhar da Clínica (visão biomédica) e corrobora com uma visão do todo. Atualmente a ciência com o advento da física quântica, demonstra a eficácia das PICS, ao qual o meio acadêmico ainda que gradualmente, inicia um movimento de absorver e internalizar em suas práticas e técnicas de ensino/aprendizagem.

Entende-se assim que não há uma separação tão rígida entre matéria e espírito, energia e emoção, influenciadas por exemplo pela "Teoria das cordas" comprovadamente aceitas no campo da física, possibilitando, uma maior bagagem para o âmbito das Terapias Complementares (CARREGA, 2012).

Segundo o Ministério da Saúde considerando a atenção básica e os serviços de média e alta complexidade, existem atualmente 9.350 estabelecimentos de saúde no país, ofertando $56 \%$ dos atendimentos individuais e coletivos em Práticas Integrativas e Complementares nos municípios brasileiros, compondo 8.239 (19\%) estabelecimentos na Atenção Básica que ofertam PICS, distribuídos em 3.173 municípios. As Práticas Integrativas e Complementares estão presentes em quase $54 \%$ dos municípios brasileiros, distribuídos pelos 27 estados e Distrito Federal e todas as capitais brasileiras (MS, 2018).

Nota-se assim a aproximação das Práticas Integrativas e Complementares à Política de Promoção da Saúde e o quanto isso é benéfico para atenção básica e fortalecimento do SUS. A política traz diretrizes gerais para a incorporação das práticas nos serviços e compete ao gestor municipal elaborar normas para inserção da PNPIC na rede municipal de saúde. Os recursos para as PICS integram o Piso da Atenção Básica (PAB) de cada município, podendo o gestor local aplicá-los de acordo com sua prioridade mas até que esse resultado chegue até a população existem pontes que precisam ser ultrapassadas.

Em contraste, com a realidade da oferta dessas terapêuticas, em países como; China, Índia, Indonésia, Madagascar, Mongólia e até em países, ainda que de forma discreta como Estados Unidos, que se utilizam da yoga e acupuntura como meios de ressocialização de jovens, os investimentos concentram-se nos níveis primários de atenção e incluem majoritariamente o uso de plantas medicinais, acupuntura e homeopatia.

O desconhecimento de alguns profissionais da saúde, sobre as terapias complementares pode ser responsável por conceitos equivocados, o que pode gerar dificuldades na relação médico-paciente e com colegas praticantes 
dessas especialidades como afirma Thiago e Tesser (2010), demonstrando um grande paradigma social e cultural dentro do país ao julgar que o Brasil já é reconhecido internacionalmente pelos esforços que emprega com as PNPICS na atenção básica.

Oliveira et al. (2017), em sua discussão argumenta que a consolidação de tais práticas é uma questão de cidadania e revela-se mediante o favorecimento da participação popular, não só no entendimento destas intervenções, mas também no sentido de tornar o usuário um agente ativo no cuidado à saúde colocando em pauta a importância dessas práticas no seu município perante o gestor atuante bem como a diversificação das mesmas nos territórios, reforça ainda essa importância ao contextualizar as PNPIC na prática, não só na atenção básica como na média e alta complexidade a abordagem da temática nas instituições de saúde em formato curricular.

Existem poucos serviços de fitoterapia cadastrados no Cadastro Nacional de Estabelecimentos em Saúde CNES, a Política de Medicamentos Fitoterápicos no SUS é ainda polêmica e tem sido alvo de críticas, principalmente porque há poucos estudos de efetividade. Mesmo com os vários incentivos da OMS, os profissionais da atenção básica diferenciados pelo contato mais próximo ao paciente e por trabalhar diretamente com os condicionantes e determinantes em relação a uma população adscrita tem o papel de divulgadores dessas terapêutica a medida em que são empoderados de seu conhecimento (SOUSA et al., 2012).

A acupuntura apesar de ser uma da PICS bem difundidas no SUS,tem sua utilização ainda restrita no SUS, tanto na atenção primária à saúde como na atenção secundária. Por ser um recurso de baixo custo para os serviços públicos, sua utilização poderia contribuir para melhor redistribuição do orçamento destinado às Secretarias de Saúde (PARANAGUÁ et al., 2009)(SILVA; TESSER, 2013).

Alguns benefícios destacados na utilização dessas práticas são: a validação do conhecimento popular da comunidade sobre o uso das plantas medicinais; o estreitamento do vínculo entre a comunidade e a equipe de saúde; a troca de saberes e a construção do conhecimento sobre plantas medicinais gerada com a interação entre esses agentes; o empoderamento da população e dos profissionais de saúde em relação à forma de cuidado estimulando sua autonomia e corresponsabilização; possibilidade da redução da medicalização excessiva; e o fortalecimento do princípio da integralidade exercido através da ampliação do olhar, do aumento de recursos terapêuticos e de ofertas de cuidado (OLIVEIRA, 2017).

Em sua maioria, as práticas integrativas e complementares em saúde, estão situadas no âmbito da atenção básica, dispostas entre as terapias mais comuns como yoga, acupuntura e o Tai Chi Chuan, a divulgação dessas práticas pelos agentes comunitários de saúde para a população é de fundamental importância, já que são eles a ponta dessa rede de atenção em saúde ampliada, 
que visa tornar o sujeito copartícipe do seu próprio cuidado (PARANAGUÁ et al., 2009).

Evidências científicas por todo o mundo já existem em que comprovam a eficiência das Terapias Complementares e Integrativas de Saúde, práticas e terapias seculares, que perpetuam pelo saber muitas vezes popular, como por exemplo a fitoterapia, que é a utilização do poder medicinal das plantas no processo saúde-doença, as PICS podem ser consideradas como uma forma de promover a saúde e não tão somente práticas em âmbito terminal, que reconhece e valoriza os determinantes e condicionantes da saúde. Assim a institucionalização das PICS no SUS atende a uma demanda social e a garantia de um direito de escolha de diferentes abordagens de cuidado.

É oportuno destacar que não se trata de enaltecer uma proposta terapêutica em detrimento de outras, mesmo porque, o pensamento sistêmico que embasa as PICS pressupõe abertura ao diálogo entre diferentes concepções, práticas e saberes. Trata-se de potencializar as benéficas que cada terapêutica podem oferecer à população, no âmbito da saúde pública visando contrapor uma cultura de medicalização, muitas vezes desnecessários e estabelecendo uma nova cultura que preza pela promoção da saúde, a prevenção de seus agravos como aborda a OMS em seu conceito de saúde.

Essas práticas se relacionam com as políticas públicas de saúde, o que comprova a complementaridade entre as políticas fator fundamental para a eficácia de suas políticas como a Política de Humanização, a própria Política de Atenção Básica aliadas também a Política de Educação Continuada, bem com o estímulo das terapêuticas no ensino-aprendizagem. Possibilitando aos futuros profissionais da área saúde, não só conhecimentos sobre as técnicas terapêuticas, mas também por atitudes cotidianas, seja ela na atenção básica ou nos outros níveis de complexidade da saúde, de forma integral diminuindo danos, sendo resolutivo e permitindo a participação do sujeito no próprio auto cuidado de formas menos invasivas.

Mesmo com todo avanço da PNPIC na última década no Brasil, continua sendo condição fundamental para sua efetiva implantação, estimular nos territórios, espaços de fortalecimento do debate sobre as práticas e trocar experiências com gestores de outros municípios/estados que tenham as PICS ofertadas pelo SUS (MS, 2018).

\section{CONCLUSÃO}

O estudo demonstra que a expansão, ainda que a passos lentos, das Terapias Complementares e Integrativas na saúde pública, resulta de esforços alcançados quando diferentes procedimentos são alinhados para promover a cura dos pacientes. A partir da visão de uma cura mais ampla, os resultados são mais eficazes, podendo desde que bem direcionados, serem aplicadas por 
profissionais médicos, enfermeiros, nutricionistas, fisioterapeutas, psicólogos e demais profissionais da saúde.

As publicações encontradas remetem a uma similaridade entre pontos importantes que precisam ser levados em consideração quando se avalia as Práticas Complementares e Integrativas e sua implementação na atenção básica, desenvolvimento e fomento de pesquisa e o ensino curricular nas academias, bem como o desconhecimento dos profissionais de saúde.

A acupuntura já reconhecida como especialidade médica, possui singular predileção no campo da saúde e nas indicações médicas, a julgar o embate ao qual permeia as PNPICS ao qual o Conselho de Medica, recua diante a implementação de algumas práticas, contestando sua eficácia através de estudos randomizados de populações, além de alguns estudiosos defenderem a acupuntura no Sus como um ato médico. Em contrapartida a homeopatia como especialidade, cresce e se expande na área acadêmica, formado médicos que defendem não só o uso das PNPICS na saúde, bem como sua prática por qualquer profissional especializado e habilitado para tal.

O que traz mudanças na relação entre, os profissionais da saúde e seus pacientes, isso por que a relação deixa de ser apenas específica. Os especialistas acreditam que desequilíbrios mentais e emocionais geram doenças. Assim como enfermidades físicas podem desencadear uma série de complicações psicoemocionais, como depressão e ansiedade. Dessa forma, a Medicina Integrativa busca curar o paciente cuidando de todas as dimensões da sua existência.

Apesar de ser uma política ainda nova, datada de 2006, observa-se de um grande potencial quando aliada a medicina alopática, sendo para isso necessário investimentos, em divulgação para a população, qualificação desses profissionais através da educação continuada, incentivo a pesquisas e das prefeituras para a implementação desta política no Município. Iniciativas que diferente do que algumas correntes de pensamento defendem, seria menos oneroso seu efeito a longo prazo aos caixas públicos, o que poderia contribuir para melhor redistribuição do orçamento destinado às Secretarias de Saúde, bem como, para melhor qualidade de vida dos pacientes.

\section{REFERÊNCIAS}

AMADO, D.; ROCHA, P. R.; UGARTE, O.; FERRAZ, C.; LIMA, M.; CARVALHO, F. Política Nacional de Práticas Integrativas e Complementares no Sistema Único de Saúde 10 anos: avanços e perspectivas. JMPHC | Journal of Management \& Primary Health Care I ISSN 2179-6750, v. 8, n. 2, p. 290-308, 22 ago. 2018.

ANDRADE, LOM., and BARRETO, ICHC. Promoção da saúde e cidades/municípios saudáveis: propostas de articulação entre saúde e ambiente. In: MINAYO, MCS., and MIRANDA, AC., orgs. Saúde e ambiente sustentável: estreitando nós [online]. Rio de 
Janeiro: Editora FIOCRUZ, 2002, pp. 150-171. ISBN 978-85-7541-366-1. Available from SciELO Books.

ARAÚJO, Janieiry Lima de; PAZ, Elisabete Pimenta Araujo; MOREIRA, Thereza Maria Magalhães. Hermeneutics and health: reflections on the thinking of Hans-Georg Gadamer. Revista da Escola de Enfermagem da USP, v. 46, n. 1, p. 200-207, 2012.

AROUCA, Antônio Sérgio da Silva. O dilema preventivista. São Paulo: Unesp: Rio de Janeiro: Fiocruz, 2003.

BRASIL.MinistériodaSaúde.Evoluçãoinstitucionaldasaúdepública,Brasília,1977.

Aiub M, Neves LP. Saúde: uma abordagem filosófica. Cadernos do Centro Universitário São Camilo [Online]. 2005; 11(1) 94-102. Disponível em: http:/ / www. institutointersecao.com/saude.doc.

BRASIL. Ministério da Saúde. Secretaria de Atenção à Saúde. Departamento de Atenção Básica. Manual de implantação de serviços de práticas integrativas e complementares no SUS / Ministério da Saúde, Secretaria de Atenção à Saúde, Departamento de Atenção Básica. - Brasília : Ministério da Saúde, 2018.

BRASIL. Ministério da Saúde. Secretaria de Atenção à Saúde. Departamento de Atenção Básica. Política nacional de práticas integrativas e complementares no SUS : atitude de ampliação de acesso / Ministério da Saúde. Secretaria de Atenção à Saúde. Departamento de Atenção Básica. - 2. ed. - Brasília : Ministério da Saúde, 2015.

BRASIL. Ministério da Saúde. Secretaria de Atenção à Saúde. Departamento de Atenção Básica. Política nacional de práticas integrativas e complementares no SUS: atitude e ampliação de acesso. Brasília, DF: Ministério da Saúde; 2006. 92 p. (Série B. Textos básicos de saúde). Disponível em: http://bvsms.saude.gov.br/bvs/ publicacoes/pnpic.pdf.

BRASIL. Ministério da Saúde. Secretaria de Atenção à Saúde. Departamento de Atenção Básica. Política nacional de práticas integrativas e complementares no SUS PNPICSUS. Brasília, DF, 2006.

BRITO, Fabiana Medeiros et al. Fitoterapia na atenção básica: estudo com profissionais enfermeiros Phytotherapy in primary care: study with nurse professionals. Revista de Pesquisa: Cuidado é Fundamental Online, [S.1.], v. 9, n. 2, p. 480-487, apr. 2017. ISSN.

CAPRA F. O ponto de mutação: a ciência, a sociedade e a cultura emergente. São Paulo (SP): Cultura; 1982. [ Links ]

CARREGA, Douglas de Aquino. Mecânica quântica e sua relação com terapias alternativas. 2012. 1 CD-ROM. Trabalho de conclusão de curso (bacharelado - Física Médica) - Universidade Estadual Paulista Julio de Mesquita Filho, Instituto de Biociências de Botucatu, 2012. Disponível em: <http://hdl.handle.net/11449/118556> 


\section{CRESCE 46\% PROCURA POR PRÁTICAS INTEGRATIVAS COMPLEMENTARES}

NO SUS. Portal da Saúde, 2019.http:/ / portalms.saude.gov.br/noticias/agenciasaude/45294-cresce-46-procura-por-práticas-integrativas-no-sus-2/>Acesso em 15 de Mar. de 2019.

Esplanada dos Ministérios, Bloco G, Edifício SEDE $7{ }^{\circ}$ Andar - CEP: 70058-900 - Brasília -DF.Disponível.em:<http:/ / dab.saude.gov.br/portaldab/noticias. php?conteudo=_\&cod=2205 acesso em 29 de março de 2019.

GUTIERREZ PR, OBERDIEK HI. Concepções sobre a saúde e a doença. In: Andrade SM, Soares DA, Cordoni Junior L, organizadores. Bases da Saúde Coletiva. Londrina: UEL; 2001.

HISTÓRIA DA OMS. Disponível em:http:/ /www.who.int/about/history/en/index. html. Acesso em: 17. marc.2019.

ISCHKANIAN, Paula Cristina. Práticas integrativas e complementares para a promoção da saúde. 2011. Dissertação (Mestrado em Serviços de Saúde Pública) - Faculdade de Saúde Pública, Universidade de São Paulo, São Paulo, 2011. doi:10.11606/D.6.2011.tde-13092011-095744. Acesso em: 2019-03-20ookim4ni n.

LINDEMBERG MA. Saúde- doença: conhecimento, poder, cultura, ciência e história. Práxis em saúde coletiva [Online]. 2006. Disponível em: http:/ / psaudecoletiva. blogspot.com.br/2009/04/saude-doenca-conhecimento-poder cultura.html.

LO, Suzane Cristina Costa; SANTANA, Raíra Gomes de; SANTOS, Déborah Cardozo dos e ALVIM, Neide Aparecida Titonelli. Práticas complementares de saúde e os desafios de sua aplicabilidade no hospital: visão de enfermeiros. Rev. bras. enferm. [online]. 2013, vol.66, n.6 [citado 2019-02-21], pp.840-846. Disponível em: <http:/ / www.scielo.br/scielo.php?script=sci_arttext\&pid=S0034-71672013000600005\&lng=pt $\& n r m=i s o>$.

LOURENÇO L.F.L., DANKZUC, R.F.T., PAINNAZER, D., JUNIOR, N.F.P., MAIA, A.R.C.R., \& SANTOS,E.K.A. (2014). A Historicidade filosófica do conceito saúde. Revista Eletrônica História da Enfermagem,1, 17-35.Z

LUZ, M. T. A arte de curar versus a ciência das doenças: história social da Homeopatia no Brasil. São Paulo: Dynamis Editorial, 1996. 342p.Z

MELO, Suzane Cristina Costa; SANTANA, Raíra Gomes de; SANTOS, Déborah Cardozo dos and ALVIM, Neide Aparecida Titonelli. Práticas complementares de saúde e os desafios de sua aplicabilidade no hospital: visão de enfermeiros. Rev. bras. enferm.[online]. 2013, vol.66, n.6 [cited 2019-02-21], pp.840-846. Available from: <http:/ / www.scielo.br/scielo.php?script=sci_arttext\&pid=S003471672013000600005\&lng=en\&nrm=iso $>$.ISSN0034-7167.http:/ / dx.doi.org/10.1590/ S0034-71672013000600005Z

MENDES, Isabel Amélia Costa. Desenvolvimento e saúde: uma declaração de Alma-Ata e posterior posteriores. Rev. Latino-Am. Enfermagem, Ribeirão Preto, 
v. 12, n. 3, p. 447-448, junho de 2004. Disponível em <http:/ / www.scielo.br/scielo. php?script=sci_arttext\&pid=S0104-11692004000300001\&lng $=$ en $\& n r m=i s o ~>$. acesso em 26 de março de 2019. http:/ / dx.doi.org/10.1590/S0104-11692004000300001.Z

Ministério da Saúde. MINISTÉRIO DA SAÚDE INCLUI 10 NOVAS PRÁTICAS INTEGRATIVASNO.SUS< disponivel em:: http:/ / portalms.saude.gov.br/noticias / agencia-saude/42737-ministerio-da-saude-inclui-10-novas-praticas-integrativas-nosus / acesso em 27 de março de $2019 . Z$

Ministério da Saúde. (Brasil). Portaria n. 971, de 03 de Maio de 2006. Aprova a Política Nacional de Práticas Integrativas e Complementares (PNPIC) no Sistema Único.Ministério da Saúde Secretaria de Atenção à Saúde Departamento de Atenção Básica,co de Saúde. Diário Oficial da União 04 maio 2006; Seção.Z

NETO, José Antonio Chehuen et al. Uso e compreensão da medicina alternativa e complementar pela população de Juiz de Fora. HU Revista, v. 36, n. 4, 2010.

OTANI, Márcia Aparecida Padovan; BARROS, Nelson Filice de. A Medicina Integrativa e a construção de um novo modelo na saúde. Ciênc. saúde coletiva, Rio de Janeiro, v. 16, n. 3, p. 1801-1811, Mar. 2011. Available from <http:/ / www.scielo. br/scielo.php?script=sci_arttext\&pid=S1413-81232011000300016\&lng=en\&nrm=iso $>$. access on 02 May 2019. http:/ / dx.doi.org/10.1590/S1413-81232011000300016

PAIVA, Carlos Henrique Assunção; TEIXEIRA, Luiz Antonio. Reforma sanitária e a criação do Sistema Único de Saúde: notas sobre contextos e autores. História, Ciências, Saúde - Manguinhos, Rio de Janeiro, v.21, n.1, jan.-mar. 2014, p.15-35.Z

PARANAGUÁ TTB, Bezerra ALQ, Souza MA, Siqueira KM. As práticas integrativas na Estratégia Saúde da Família: visão dos agentes comunitários de saúde. Rev Enferm UERJ.2009;17(1):75-80

SCLIAR, Moacyr. História do conceito de saúde. Physis [online]. 2007, vol.17, n.1 [citadoem2019-02-21],pp.29-41.Disponívelem: <http:/ / www.scielo.br/scielo. php?script=sci_arttext\&pid=S0103-73312007000100003\&lng=en\&nrm=iso $>$.ISSN01037331.http:/ /dx.doi.org/10.1590/S0103-73312007000100003.Z

SILVA, Emiliana Domingues Cunha da; TESSER, Charles Dalcanale. Experiência de pacientes com acupuntura no Sistema Único de Saúde em diferentes ambientes de cuidado e (des)medicalização social. Cad. Saúde Pública, Rio de Janeiro, v. 29, n. 11, p. 2186-2196.

SOUSA, Islândia Maria Carvalho de et al. Práticas integrativas e complementares: oferta e produção de atendimentos no SUS e em municípios selecionados. Cad.

Saúde Pública, Rio de Janeiro, v. 28, n. 11, p. 2143-2154, Nov. 2012. Available from <http://www.scielo.br/scielo.php?script=sci_arttext\&pid=S0102-311X2012001100 014\&lng=en\&nrm=iso $>$. access on 16 Apr. 2019. http:/ / dx.doi.org/10.1590/S0102311X2012001100014 Z 
TELESI JUNIOR, Emílio. Práticas integrativas e complementares em saúde, uma nova eficácia para o SUS. Estud. av. [online]. 2016, vol.30, n.86 [cited 2019-02-21], pp.99-112. Availablefrom:<http:/ / www.scielo.br/scielo.php?script=sci_arttext\&pid=S010340142016000100099\&lng=en\&nrm=iso $>$

TESSER, C. D.; BARROS, N. F. de. Medicalização social e medicina alternativa e complementar: pluralização terapêutica do Sistema Único de Saúde. Revista de Saúde Pública, São Paulo, v. 42, n. 5, p. 914-920, out. 2008.

THIAGO, Sônia de Castro S; TESSER, Charles Dalcanale. Percepção de médicos e enfermeiros da Estratégia de Saúde da Família sobre terapias complementares. Rev. Saúde Pública, São Paulo, v. 45, n. 2, p. 249-257, Apr. 2011. Available from <http:/ / www.scielo.br/scielo.php?script=sci_arttext\&pid=S0034-89102011000200003\&lng=e n\&nrm=iso >. access on 02 May 2019. Epub Jan 26, 2011. http:/ /dx.doi.org/10.1590/ S0034-89102011005000002

WESTPHAL M F. Promoção da Saúde e Prevenção de Doenças. In: Campos GWS, Minayo MC, Akerman M, Drumond Junior M, Carvalho YM. Tratado de saúde coletiva. São Paulo: Hucitec; Rio de Janeiro: Ed. Fiocruz; 2007. p. 653-663. 